\title{
A high-performance multilevel inverter with reduced power electronic devices
}

\author{
Amer Chlaihawi, Adnan Sabbar, Hur Jedi \\ Department of Electrical Engineering, University of Kufa, Iraq
}

\begin{tabular}{l} 
Article Info \\
\hline Article history: \\
Received Feb 20, 2020 \\
Revised Apr 26, 2020 \\
Accepted May 19, 2020
\end{tabular}

Keywords:

High-performance operation Multilevel inverter (MLI) Nearest level modulation (NLM)

\begin{abstract}
This paper introduces a new topology of multilevel inverter, which is able to operate at high performance. This proposed circuit achieves requirements of reduced number of switches, gate-drive circuits, and high design flexibility. In most cases fifteen-level inverters need at least twelve switches. The proposed topology has only ten switches. The inverter has a quasi-sine output voltage, which is formed by level generator and polarity changer to produce the desired voltage and current waveforms. The detailed operation of the proposed inverter is explained. The theoretical analysis and design procedure are given. Simulation results are presented to confirm the analytical approach of the proposed circuit. A 15-level and 31-level multilevel inverters were designed and tested at $50 \mathrm{~Hz}$.
\end{abstract}

This is an open access article under the CC BY-SA license.

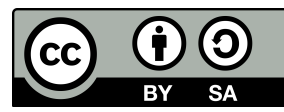

\section{Corresponding Author:}

Adnan Sabbar,

Department of Electrical Engineering,

University of Kufa, Najaf, Iraq.

Email: adnan.sabbar@uokufa.edu.iq

\section{INTRODUCTION}

With the rapid development of power electronics, the demand of power converters are high performance, low cost and high power quality applications [1-3]. Reducing the number of switches in power electronics can improve the power density and leads to low voltage stress on switches [4-7]. Multilevel converters can attain both fundamental switching frequency and high switching frequency PWM [8-10]. Therefore, multilevel inverters with separate DC sources are suited for operation at low frequency to achieve low switching losses and high efficiency [11-13]. Inverters in such application handle high voltage and extensive power. Thus, high-level inverters, which are composed of switching power devices integrated gate bipolar transistors (IGBTs), are suitable to achieve high voltage applications $[14,15]$. Most conventional multilevel inverters, such as Flying Capacitor (FC), Neutral Point Clamped (NPC), and Cascaded H-Bridge (CHB) suffer from high-voltage stress on switch, high Electro Magnetic Interference (EMI) and poor power quality output [16-18]. In order to solve these issues, a new topology of multilevel inverter is presented.

In last few decades, several authors have been increasingly focused on multilevel inverter topologies with reduction in numbers of power switches [19-23]. Topology [24] is combined of IGBT and diode causing reduction in efficiency. In addition, the losses and cost will be increased and its industrial applications will be restricted. In [25] sub-multilevel converter blocks are connected in series. This circuit consists of capacitors and four bi-directional switches are utilized in each unit. Thus, the installation area is increased in the proposed topology. Most of the multilevel inverters suffer from high voltage stresses at the power switches and require different voltage rating of the power switches. In addition, switching frequency leads to a decrease in efficiency 
due to switching losses. Therefore, the proposed topology is attractive for high-performance applications.

This work proposes a high power quality multilevel inverter with reduced in numbers of power semiconductor devices. The proposed topology can attain a large number of levels with asymmetric DC voltage sources. This topology is based on the conventional inverter that utilizes level generation and polarity change. The new circuit can be utilized for 15-level and 31-level inverter. To implement a 15-level inverter, ten IGBT switches and three dc voltage sources are selected. The multilevel inverter generates staircase voltage waveform with decreased electromagnetic compatibility (EMC) issues and low distortion. The new topology also utilizes low number of power switches and includes a low-design complexity. The described topology also shows in details the analysis of the steady-state voltage waveforms. In order to determine an appropriate characteristics of the multilevel inverter, a design procedure has been applied. The proposed circuit was simulated and tested at a frequency of $50 \mathrm{~Hz}$. A control unit of signals are used to generate fixed values of operating frequency and duty ratio. Collectively, these features make the new multilevel inverter advantageous in applications, such as AC drives and FACTS devices.

\section{ANALYSIS OF THE PROPOSED MULTILEVEL INVERTER TOPOLOGY}

Figure 1 shows the proposed multilevel inverter circuit. The proposed topology consist of level generate and polarity change. The level generation has power switch $P_{i}$ and power switch $S_{i}$, which is connected in series with the DC voltage source $V_{i}$. The circuit of polarity change is comprised H-Bridge power switches $H S_{i}$ and connected in parallel with the load. In this study, IGBT transistors, which have high switching performance, are used in the proposed topology. We focus on identifying the characteristics of the proposed inverter to provide a flexible output voltage waveform across the load of the circuit with minimum number of switches.

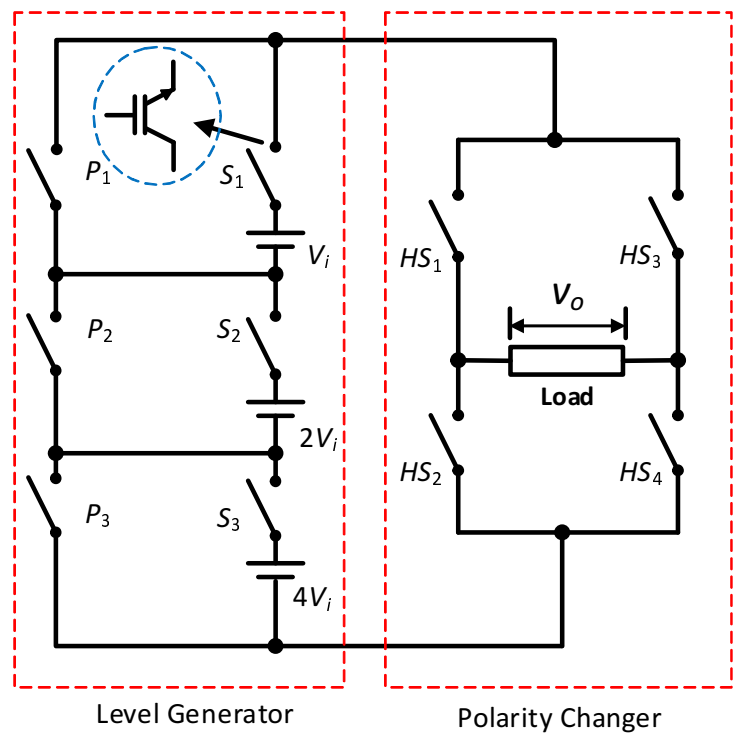

Figure 1. Proposed multilevel inverter circuit

The new topology can produce fifteen-level output during asymmetric condition. The operating modes during asymmetric operation of the circuit to obtain alternating output voltage across the load is shown in Figure 2. The proposed topology requires six switches and three DC voltage sources to generate positive-levels steps output voltage at the load as shown in the left part of the inverter. A polarity changer, which is comprised of four switches, is added to generate the negative-levels steps output voltage at the load. The switches $H S_{i}$ are utilized to reverse the polarity of the output voltage of the inverter. The analysis of the proposed circuit is based on the the ON-state and the OFF-state of the switches $P_{i}$ and $S_{i}$, respectively. The switches $H S_{1}$ and $H S_{4}$ are ON during the positive cycle of the operation, while the switches $H S_{2}$ and $H S_{4}$ are ofF during the negative cycle of the operation. 


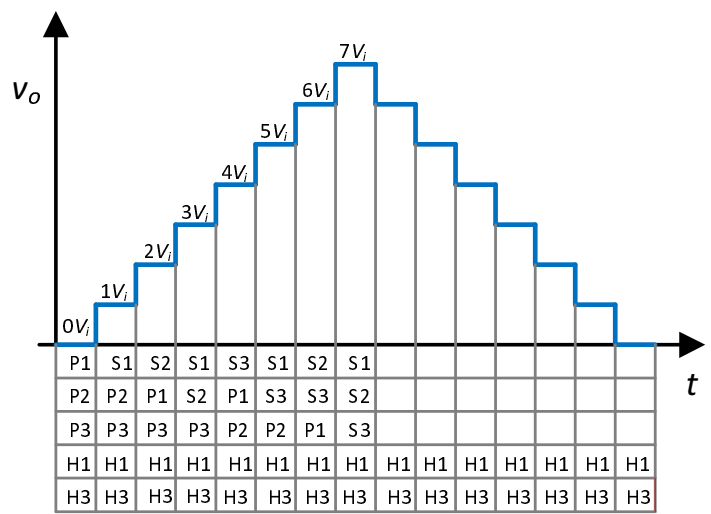

Figure 2. Operation mode of switches.

Figure 3 shows the illustrating operation of idealized steps of the circuit over a period. As can be seen, each step for output voltage is double of the voltage source $V_{i}$. The switches $P_{i}$ and $S_{i}$ of the inverter can be derived according to the control unit circuit to generate pulse width modulator waveforms as shown in Figure 4.

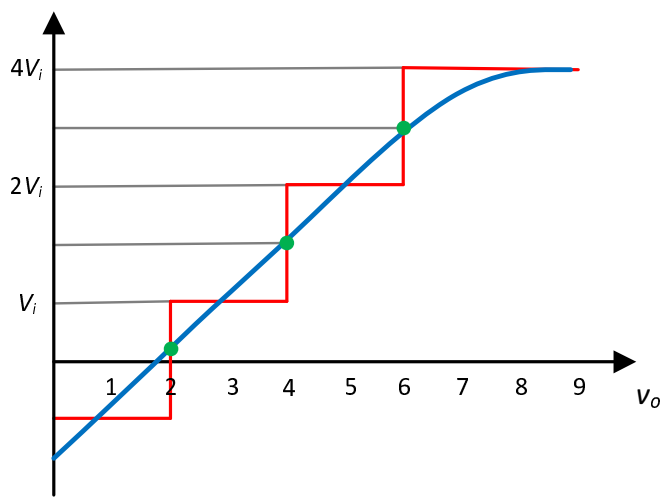

Figure 3. Level modulation technique

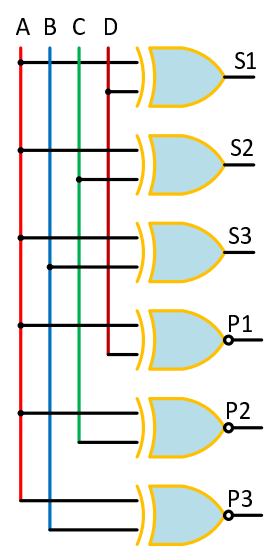

Figure 4. Control unit of signals for 15-level switches

To establish the design equations, the circuit behavior is analyzed in each interval. It is considered $V_{i}$ as a reference voltage in the proposed multilevel inverter. The number of DC voltage sources $N V$ base on the number of unit cell $m$ in the inverter

$$
N=2^{m}
$$

where, $m=0,1,2,3 \ldots i$. The steps of output voltage $D_{\text {steps }}$ can be found as

$$
D_{\text {steps }}=2^{i+2}-1 \text {. }
$$

The maximum output voltage $v_{O}$ is the sum of DC voltage sources $N$

$$
v_{O}=\left(\frac{D_{\text {steps }}-1}{2}\right) V_{i}
$$

The power switches of the proposed topology can be switched at any duty cycle $D$. It can be determined based on the specifications of the multilevel inverter. 


\section{DESIGN PROCEDURE}

A design procedure for the new multilevel inverter is presented to supply a resistive load at operating frequency $f_{s}=50 \mathrm{~Hz}$. In the design procedure, the following design parameters $V_{i}, v_{O}$, and $D$ are determined. The reference DC voltage source $V_{i}$ for 15-level and 31-level were chosen to be $45 \mathrm{~V}$ and $20 \mathrm{~V}$, respectively. Furthermore, the duty cycle of power switches is $50 \%$. The reference DC voltage $V_{i}$ can be selected basing on the application of the inverter. In the proposed circuit, the designer can easily adjust the value of duty cycle to achieve the required driven voltage waveform of the power switches. For 15-level output and step voltage $45 \mathrm{~V}$, the peak-to-peak output voltage of the multilevel inverter is varied from +312 to -312 . For the 31 -level inverter, the reference DC voltage $V_{i}=20 \mathrm{~V}$ is applied at the proposed circuit, the peak value of voltage stress is $312 \mathrm{~V}$ at duty cycle $D=50 \%$. The peak value of the voltage stress depends on the total DC source voltage on the power switch. The value of $v_{G E}$ voltage based on the characteristics of the power switch IGBT in the inverter. Therefore, it is important to select a proper driving voltage rating for the power switch. In this work, the voltage $v_{G E}$ rating of the power switch, which is utilized in the gate driver, is $20 \mathrm{~V}$. The transistor BUP306D was utilized as a IGBT power switch in circuit. The load of the proposed inverter is chosen to be a resistive load $R_{L}=50 \Omega$.

The major differences between the proposed topology and the popular multilevel inverters are the number of power switches and the type of switching. Thus, most multilevel inverter circuits operate at least twelve power switches. To operate fifteen-level inverter, the proposed multilevel inverter has six switches in the level generation and four switches in the H-bridge. Furthermore, the switching behavior of IGBT transistors in the proposed multilevel inverter can achieve high voltage applications. Therefore, the performance of the inverter can increase the efficiency of the inverter. These features show the the advantage of the new circuit. The specifications and parameters of the circuit are given in Table 1.

\begin{tabular}{cc} 
Table 1. List of parameters for multilevel inverter at $f_{s}=50 \mathrm{~Hz}$ \\
\hline Components & Value \\
\hline BUP306D & $V_{C E}=1200 \mathrm{~V}, V_{G E}=20 \mathrm{~V}, I_{C}=23 \mathrm{~A}$ \\
$R$ & $C_{\text {iss }}=1300 \mathrm{pF}, C_{\text {oss }}=100 \mathrm{pF}, C_{\text {rss }}=50 \mathrm{pF}$ \\
$\mathrm{V}_{i}$ & $50 \Omega$ \\
\hline
\end{tabular}

\section{SIMULATION RESULTS}

Based on the design methodology and the circuit operation, the proposed multilevel inverter has been verified through MatLab simulation. The performance of the proposed topology during the asymmetric operation is analyzed. A $50 \mathrm{~Hz}$ PWM signal is used to supply the power switches, and the value of duty cycle is $D=0.5$. A BUP 306D IGBT power switch with anti parallel diode $(1200 \mathrm{~V}, 23 \mathrm{~A})$ from Siemens was used as the power transistor in the multilevel inverter circuit. In order to make the circuit operates in high performance, this power switch is optimized for low switching losses and high-speed operating. The proposed topology is simulated for 15-level inverter and 31-level inverter, respectively.

\subsection{5-level multilevel inverter}

To generate appropriate switching Pulse Width Modulation schemes for the power switches, the circuit in Figure 4 is used. The fundamental frequency is utilized to generate the switching pulses in the circuit. According to the switching states, the pulses are generated at each step to drive the power switches as shown in Figure 5. If the pulses form accurately, the efficiency and harmonic distortion can be controlled effectively in the proposed multilevel inverter. The switches of H-bridge are operated in a complementary mode to produce the positive and the negative levels steps output voltage at the load. The inverter provides the AC signal with a peak magnitude $312 \mathrm{~V}$ to the load, when the dc voltage source is $45 \mathrm{~V}$. In order to observe the step voltage waveform at the output resistor, the zoomed waveform of the output voltage for the multilevel inverter is shown in Figure 6. It can be seen that the step size of the waveform is $45 \mathrm{~V}$. The step level of the inverter was captured in Figure 7. It is clear that the output voltage is close to sine waveform. The presented approach proves that the new inverter provides low-voltage stress and small-valued components. 

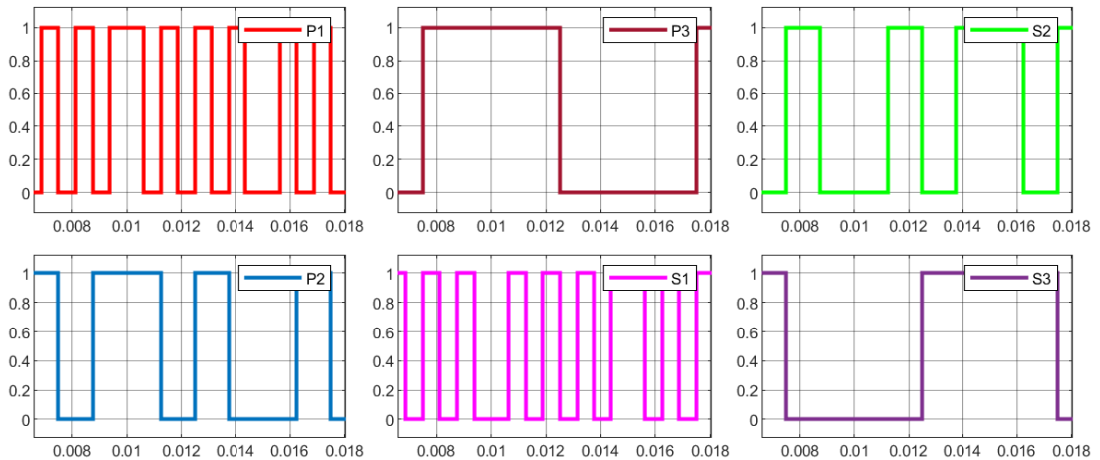

Figure 5. Simulated 15-level switching pulse waveforms of multilevel inverter

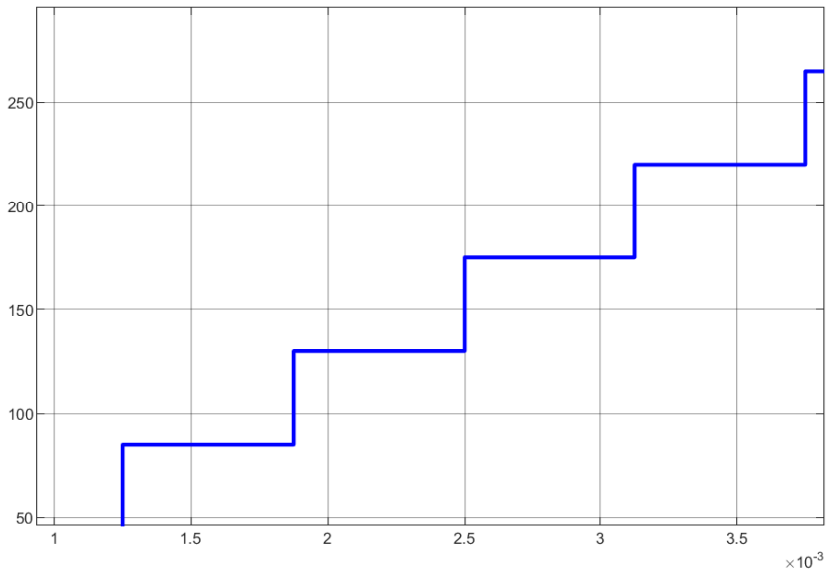

Figure 6. Simulated of 15-level zoomed output voltage waveform

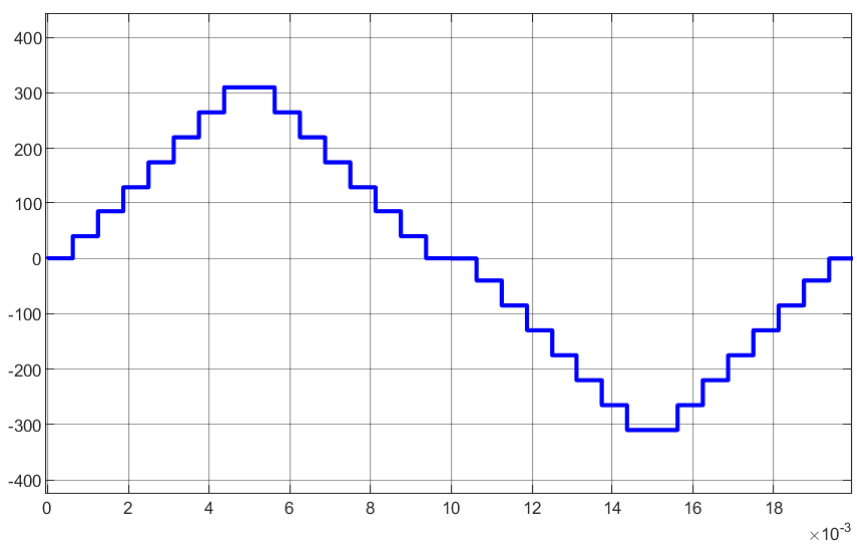

Figure 7. Simulated of 15-level multilevel inverter waveform

\subsection{1-level multilevel inverter}

The proposed topology can be utilized for 31-level to generate AC waveform close to sine signal. The power switches of 31-level circuit are derived by the control circuit to form switching pulses as shown in Figure 8. The output voltage waveform in Figure 9 shows the operation of 31-level of the proposed topology. It is clearly shows that the operation of the circuit is obtained by the level generation and change polarity circuit to supply the AC signal to the load. The maximum value of the voltage stress was measured as $312 \mathrm{~V}$ for the input voltage $V=20 \mathrm{~V}$. The peak-to-peak output voltage of the multilevel inverter across the load is varied from +185 to -185 . It can be noticed that the output voltage is close to sine waveform. 

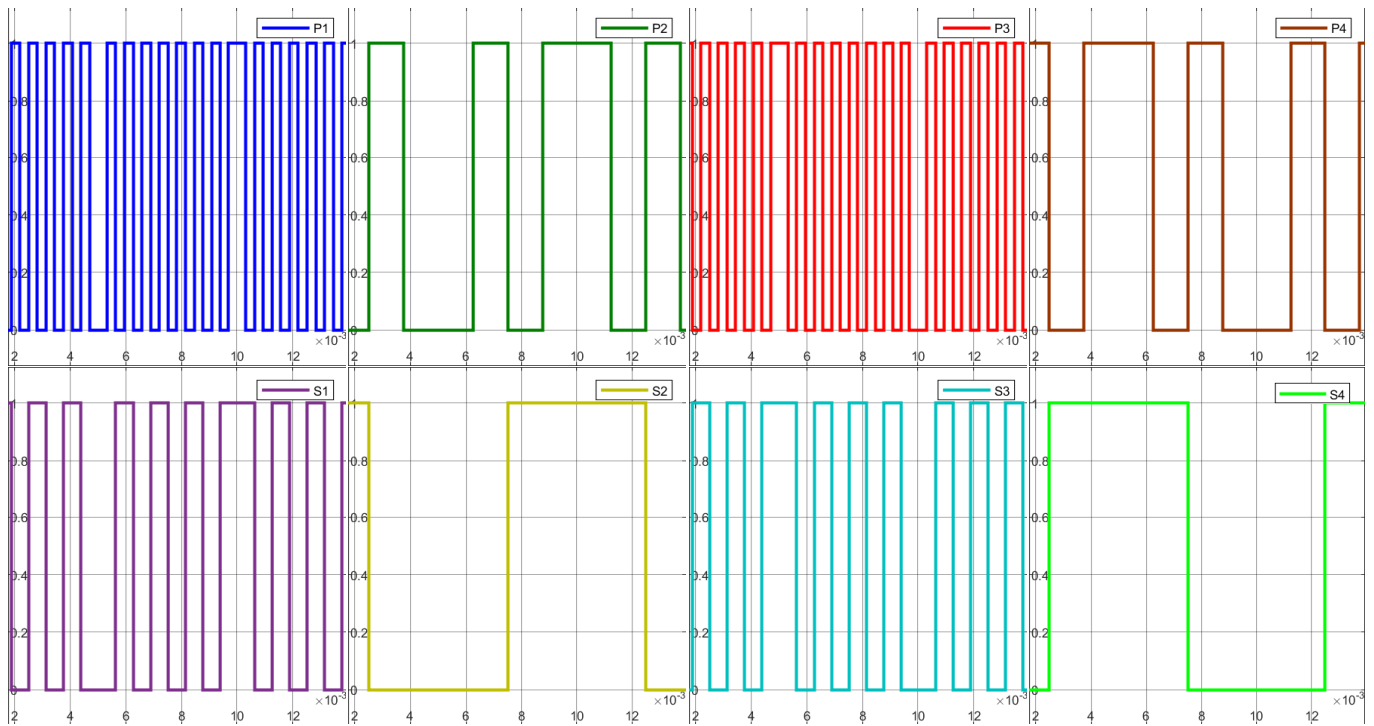

Figure 8. Simulated 31-level switching pulse waveforms of multilevel inverter

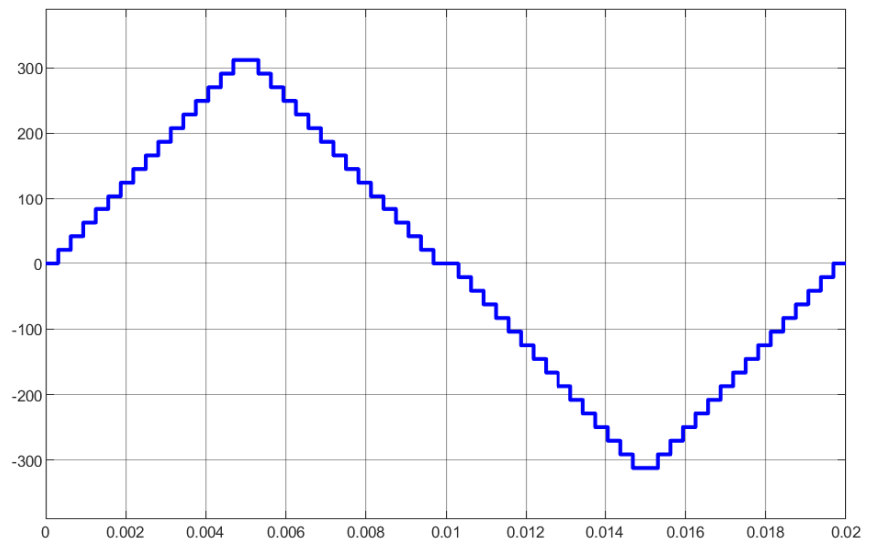

Figure 9. Simulated 31-level multilevel inverter waveform.

\section{CONCLUSION}

A new switched-mode multilevel inverter, which is derived from conventional multilevel inverter, has been introduced. This topology operates at constant duty cycle and frequency. The new topology can be designed for 15-level and 31-level inverter. An H-bridge is added in the proposed topology to generate negative voltage levels. It has a low number of power switches, low switch voltage stress, low DC voltage sources, and flexible design. The new circuit is designed to supply AC signal to the load even when low-input voltage of the inverter is available. Based on above analysis, the prototype with $50 \mathrm{~Hz}$ was designed and simulated. The simulation testing results demonstrate a good agreement between the simulations and the calculations. The proposed circuit can be used in applications that demand high performance, such as FACTS controllers and adjustable motor drives.

\section{REFERENCES}

[1] G. Ceglia, et al., "A New Simplified Multilevel Inverter Topology for DC-AC Conversion,” IEEE Transactions on Power Electronics, vol. 21, no. 5, pp. 1311-1319, Sep. 2006.

[2] A. Chlaihawi, et al., "Novel Screen Printed and Flexible Low Frequency Magneto-Electric Energy Harvester," IEEE Sensors, 2016, pp. 1-3. 
[3] A. Al-Modaffer, A. Chlaihawi and H. Wahhab, "Non-Isolated Multiple Input Multilevel Output DCDC Converter for Hybrid Power System," Indonesian Journal of Electrical Engineering and Computer Science, vol. 19, no. 2, pp. 635-643, 2020.

[4] S. Kjaer, J. Pedersen, and F. Blaabjerg, "A Review of Single-Phase Grid-Connected Inverters for Photovoltaic Modules," IEEE Transactions on Industry Applications, vol. 41, no. 5, Oct. 2005.

[5] Y. H. Liao, et al., "Newly-Constructed Simplified Single-Phase Multistring Multilevel Inverter Topology for Distributed Energy Resources," IEEE Trans. on Power Elect., vol. 26, pp. 2386-2392, 2011.

[6] A. Chaithanakulwat, "Track The Maximum Power of a Photovoltaic to Control a Cascade Five-Level Inverter a Single-Phase Grid-Connected with a Fuzzy Logic Control," International Journal of Power Electronics and Drive System, vol. 10, no. 4, pp. 1863-1874, 2019.

[7] D. Cobaleda, et al., "Low-Voltage Cascade Multilevel Inverter with GaN Devices for Energy Storage System,” IEEE International Conference on Power Electronics and Drive Systems, pp. 1-5, 2019.

[8] N. Prabaharan, A. Fathima, and K. Palanisamy, "New Hybrid Multilevel Inverter with Reduced Switch Count Using Carrier Based Pulse Width Modulation Technique," IEEE Energy Conversion Conference, pp. 176-180, 2015.

[9] Y. Babkrani , A. Naddami and M. Hilal, "A Smart Cascaded H-bridge Multilevel Inverter with an Optimized Modulation Techniques Increasing the Quality and Reducing Harmonics," International Journal of Power Electronics and Drive System, vol. 10, no. 4, pp. 1852-1862, 2019.

[10] C. Barth et al., "Design and Control of a GaN-based, 13-Level, Flying Capacitor Multilevel Inverter," IEEE Journal of Emerging and Selected Topics in Power Electronics, 2019.

[11] A Sawan and Aspalli, "Cascaded Multilevel Inverter Topology with Reduced number of Switches," International Journal Science and Research, vol. 6, no. 5, pp. 1309-1327, Sep. 2017.

[12] A. Chlaihawi, "Genetic Algorithm Error Criteria as Applied to PID Controller DC-DC Buck Converter Parameters: an Investigation," Materials Sci. and Engine. Conf., vol. 671, pp. 1-10, 2009.

[13] B. Xiao, et al., "Modular Cascaded H-bridge Multilevel PV Inverter with Distributed MPPT for GridConnected Applications," IEEE Trans. on Industry App., vol 51, no. 2, pp. 1722-1731, 2015.

[14] J. Rodriguez, et al., "Multilevel Converters: an Enabling Technology for High-Power Applications," Proceedings of IEEE, vol. 97, no. 11, pp. 1786-1817, 2009.

[15] C. Rech and J. Pinheiro, "Hybrid multilevel converters: unified analysis and design considerations," IEEE Transaction on Industrial Electronics, vol. 54, no. 2, pp. 1092-1104, Apr. 2007.

[16] E. Najafi, and A. Yatim, "Design and Implementation of a New Multilevel Inverter Topology," IEEE Transactions on Industrial Electronics, vol. 59, no. 11, pp. 4148-4154, Nov. 2012.

[17] N. Prabaharan and K. Palanisamy. "A Comprehensive Review on Reduced Switch Multilevel Inverter Topologies, Modulation Techniques and Applications," Renew. and Sustain. Energy Reviews, vol. 76, pp. 1248-1282, 2017.

[18] N. Rahim, K. Chaniago, and J. Selvaraj, "Single-Phase Seven-Grid-Connected Inverter for Photovoltaic System," IEEE Transactions on Industrial Electronics, vol. 58, no. 6, pp. 2435-2443, Jun. 2011.

[19] J. Ebrahimi, E. Babaei, and G. Gharehpetian, "A New Multilevel Converter Topology with Reduced Number of Power Electronic Components," IEEE Transactions on Industrial Electronics, vol. 59, no. 2, pp. 655-667, Feb. 2012.

[20] J. Rodriguez, J. Lai, and F. Peng, "Multilevel Inverters: Survey of Topologies, Controls, and Applications," IEEE Trans. Industrial App., vol. 49, no. 4, pp. 724-738, Aug. 2002.

[21] M. Malinowski, et al., "A Survey on Cascaded Multilevel Inverters," IEEE Transactions on Industrial Electronics, vol. 57, no. 7, pp. 2197-2206, Jul. 2010.

[22] Y. Liu, H. Hong, and A. Q. Huang, "Real-Time Algorithm for Minimizing THD in Multilevel Inverters with Unequal or Varying Voltage Steps Under Staircase Modulation," IEEE Transactions on Industrial Electronics, vol. 56, no. 6, pp. 2249-2258, Jun. 2009.

[23] J. Rodriguez, et al., "A New Modulation Method to Reduce Common Mode Voltages in Multilevel Inverters," IEEE Transactions on Industrial Electronics, vol. 51, no. 10, pp. 834-839, Aug. 2004.

[24] A. Ajami, et al., "Developed Cascaded Multilevel Inverter Topology to Minimize the Number of Circuit Devices and Voltage Stresses of Switches," IET Power Electronics, vol. 7, no. 2, pp. 459-466, 2014.

[25] E. Babaei, "A Cascade Multilevel Converter Topology with Reduced Number of Switches," IEEE Transactions on Power Electronics, vol. 23, no. 6, Nov. 2008. 